RESEARCH REPORT

\title{
Are intrinsic motivational factors of work associated with functional incapacity similarly regardless of the country?
}

\author{
A Väänänen, K Pahkin, P Huuhtanen, M Kivimäki, J Vahtera, T Theorell, R Kalimo
}

J Epidemiol Community Health 2005;59:858-863. doi: 10.1136/jech.2004.030106

Background: Many psychosocial models of wellbeing at work emphasise the role of intrinsic motivational factors such as job autonomy, job complexity, and innovativeness. However, little is known about whether the employees of multinational enterprises differ from country to country with regard to intrinsic motivational factors, and whether these factors are associated with wellbeing similarly in the different countries. The purpose of this study was to examine the level of intrinsic motivational factors and their impact on functional incapacity in different countries in a multinational corporation.

See end of article for authors' affiliations

Correspondence to:

Dr A Väänänen, Finnish Institute of Occupational Health, Department of Psychology,

Topeliuksenkatu 41 a A, Fl-00250 Helsinki, Finland; Ari.Vaananen@ HIl.fi

Accepted for publication 4 May 2005
Methods: In 2000, data were collected from a globally operating corporation with a questionnaire survey. The participants were 13795 employees (response rate 59\%; 56\% under age 45; 80\% men; 61\% blue collar employees), who worked in similar industrial occupations in five countries (Canada, China, Finland, France, and Sweden).

Results: The Chinese employees reported higher autonomy and lower complexity at work than the employees from the other countries. After adjustment for age, sex, socioeconomic status, and physical work environment, job autonomy, and job complexity at work were associated with functional incapacity in most countries, whereas in China the impact was significantly stronger. In Finland and in China employees with low innovativeness at work were more prone to functional incapacity than corresponding employees in other countries.

Conclusions: The level of intrinsic motivational factors varied between the Chinese employees and those in other countries. In line with theoretical notions, the relation between intrinsic motivational factors of work and functional incapacity followed a similar pattern in the different countries. However, these country specific results show that a culture specific approach to employee wellbeing should also be applied.
L ack of innovativeness, job autonomy, and job complexity has been regarded in several psychosocial theories on Work related health to be risks to employee wellbeing and health. ${ }^{1-4}$ Empirical support for this view has been mainly found from welfare states such as Finland, ${ }^{56}$ Sweden, ${ }^{78}$ Belgium, ${ }^{9}$ the Netherlands, ${ }^{10}{ }^{11}$ and the UK. ${ }^{12}{ }^{13}$ Recent evidence from post-socialist European countries also points to the importance of these types of factors for employee health. ${ }^{14}$

From the sociocultural perspective, these types of work characteristics can be defined as intrinsic motivational factors of work. These are closely related to modern western employees' need for greater individual control, personal growth, and self mastery, a view that has also been present in the seminal western theories of psychology on individual wellbeing. ${ }^{15-18}$ It thus seems that the health conserving intrinsic motivational factors of work are associated with typically occidental psychological characteristics of wellbeing desired and valued by European and Northern American workers.

In cross cultural psychology and anthropology, however, it has been suggested that job characteristics such as autonomy or innovativeness might not be so relevant sources of wellbeing in all countries, but their relevance may depend on the cultural and socioeconomic environment in which employees work and live. ${ }^{19} 20$ This line of arguing suggests that in developed individualistic countries with good achieved physical and financial wellbeing, workers may value more the intrinsic motivational factors emphasised by western psychosocial approaches on employee wellbeing, ${ }^{21}{ }^{22}$ while in economically less developed countries, the role of external motivational factors such as monetary rewards or a clean work environment may be more salient.
Our study was motivated by the fact that no cross national comparisons between countries with different sociocultural background have been conducted on intrinsic motivational factors of work and workers' wellbeing among employees having similar occupations and working in the same employment sector in the multinational companies. To examine the role of the national culture in the interrelation between intrinsic motivational factors and employee wellbeing, the similarity of work and the sector of employment between the countries is crucial, because otherwise various national characteristics of work environment and the employment sector could explain the differences in the associations between the countries. Previous studies on intrinsic motivational factors and employee wellbeing have been affected by the different research instruments used, and the different types of organisational cultures. This has made comparisons between the studies very difficult. Moreover, earlier cross cultural studies have suggested that national cultures vary in terms of intrinsic motivational factors, ${ }^{23-25}$ but it has not been investigated whether there is a cross national variation in intrinsic motivational factors between countries in the multinational organisations of the new millennium. Finally, cross national research on wellbeing at work has mainly focused on a few western nations and Japan, ${ }^{26}{ }^{27}$ and studies on national characteristics of work related wellbeing have been scarce..$^{28}$ Especially in multinational corporations, there is an increasing need to know more about the cultural contingence of employees' wellbeing and health.

To overcome some of the limitations of prior research, we examined the intrinsic motivational factors of work and self rated functional wellbeing among industrial employees in five countries working in the same company, in similar occupations, and having a similar type of physical work 
environment. We formulated the following research questions: (1) Do the levels of intrinsic motivational factors of work and functional incapacity vary in the global corporation by country? (2) Do the associations between intrinsic motivational factors and functional incapacity follow similar patterns in different countries, and are there some country specific factors associated with functional incapacity.

\section{METHODS}

\section{Study design and participants}

Data were collected with a questionnaire on psychosocial factors and wellbeing in the autumn of 2000 in 16 countries (each country $>50$ employees). The questionnaire was available in 10 languages. To guarantee the validity of the different language versions, the official licensed language translators first translated the questionnaires from the original English version to each language, and after this, the translated versions were translated back to English by other licensed translators. To verify the correspondence of the different translations of the questionnaire, the versions were compared and the final corrections to the language versions were made. Five countries, which filled well the selection criteria (similar work tasks in each country, $>45 \%$ response rate, $>400$ participants, all the factors of interest assessed), formed the study population.

Table 1 gives the study populations and the background characteristics of the participants. The total study population comprised 13795 employees of a forest industry corporation. The overall response rate in these countries was $58 \%$. Most of the white collar employees were managers, supervisors, and professionals, or worked in the lower white collar occupations such as secretaries, technical assistants, and laboratory technicians. Most of the blue collar employees were factory workers on the production line, process control operators, cleaners, laboratory assistants, or they worked in maintenance occupations in the industrial halls and offices. White collar employees worked predominately only in the day time, while most of the blue collar employees in all countries worked in rotating shifts including night work. Both white collar and blue collar employees have been found to be vulnerable to various psychosocial risks in previous studies within the Finnish units of the enterprise. ${ }^{30-32}$ The study was approved by the ethics committee of the Finnish Institute of Occupational Health.

\section{Intrinsic motivational factors}

Innovativeness $(\alpha=0.80)$ was measured by seven items assessing encouraging atmosphere, development of new ways of action, collaboration in implementing ideas, and the response to new proposals in the work unit.

Job complexity $(\alpha=0.79)$ was measured by five items assessing the variety of work tasks, utilisation of skills, cognitive challenges, and the necessity to learn new things.

Job autonomy $(\alpha=0.78)$ was measured by five items assessing control over one's work tasks, work pace, work method, freedom to leave one's work post, and to set one's own goals.
These scales have been used in several studies previously, and their face validity and predictive validity have been shown to be good..$^{31}{ }^{32}$ The test-retest correlations have been high in long term follow ups. In this study, the internal consistency of the scales was good across the countries $(\alpha$ values $>0.70$ ).

\section{Functional incapacity}

Functional incapacity was measured with three items $(\alpha=0.77)$ measuring physical, mental, and comparative ability to perform duties. A Likert-type scale ranging from 1 (very good) to 5 (very poor) was used. The items of functional incapacity were derived from the work ability index. ${ }^{33}$ The predictive validities of the work ability index (a total score of seven items) has been found to be good in Finnish studies ${ }^{34}$ and functional incapacity has shown high four year testretest correlations $(r>0.60) .{ }^{32}$ The scales of intrinsic motivational factors and functional incapacity can be found in the appendix.

\section{Background variables}

Data on age, sex, and socioeconomic status (SES: blue collar compared with white collar) were drawn from the questionnaire. To study the physical hazards in the work environment, we measured traditional exposures at work (for example, vibration, noise, dirtiness, abnormal temperature, danger of accidents) using an 11 item scale $(\alpha=0.89)$. The format of asking was "Are the following elements found in your work environment?" ( $1=$ not disturbingly or not at all; 2 = somewhat disturbingly, 3 =very disturbingly or hazardous to health). Data on total fertility rate, unemployment rate, gross domestic product (GDP) per capita, and the Gini coefficient (wealth inequality) by country were collected from the statistics of the OECD and the United Nations (table 2). ${ }^{35-37}$

\section{Statistical methods}

The sum scales were formed by using factor analysis, and their reliability was assessed with Cronbach's $\alpha$ (across countries and by country). Means (M) and standard errors (SE) were calculated for the intrinsic motivational factors and functional incapacity according to country and in the total sample of all five countries (research questions 1 and 2), and tests for country differences were made using general lineal models (GLM). To study the third research question, the independent variables were trichotomised into tertiles, and the dependent variables were dichotomised (low (30\%) compared with intermediate or good functional capacity $(70 \%))$. Binary logistic regression analyses were performed (odds ratios (OR) and their 95\% confidence intervals $(95 \%$ CI)). In the regression models, the effect of age $(<45 v \geqslant 45)$, sex, grade of employment (white collar $v$ blue collar employees), and physical work environment (a dichtomised measure: $20 \%$ demanding $v 80 \%$ not demanding) were used as confounders. In the pooled analysis, also country level adjustments were made for fertility, unemployment, GDB per capita, and wealth inequality. They were used as continuous

Table 1 Background characteristics in five countries (the proportions in percentages)

\begin{tabular}{|c|c|c|c|c|c|c|}
\hline & $\begin{array}{l}\text { Canada } \\
n=475 \\
(\mathrm{RR}=71.9)\end{array}$ & $\begin{array}{l}\text { China } \\
n=686 \\
(\mathrm{RR}=83.7)\end{array}$ & $\begin{array}{l}\text { Finland } \\
n=7771 \\
(R R=60.7)\end{array}$ & $\begin{array}{l}\text { France } \\
n=554 \\
(\mathrm{RR}=45.2)\end{array}$ & $\begin{array}{l}\text { Sweden } \\
n=4647 \\
(\mathrm{RR}=54.8)\end{array}$ & $\begin{array}{l}\text { Total } \\
n=14133 \\
(R R=58.0)\end{array}$ \\
\hline$>45$ years of age & 48.1 & 11.0 & 53.8 & 35.0 & 43.6 & 44.5 \\
\hline Male employees & 89.5 & 82.0 & 77.4 & 78.6 & 77.6 & 80.1 \\
\hline Blue collar employees & 72.4 & 63.0 & 61.8 & 36.6 & 59.5 & 60.7 \\
\hline Physical hazards in work environment & 43.3 & 42.3 & 27.0 & 57.4 & 37.2 & 33.0 \\
\hline
\end{tabular}


Table 2 Rate of country level control variables used in the pooled analyses

\begin{tabular}{|c|c|c|c|c|}
\hline & Unemployment rate† & GDP per capitał & Fertility rate§ & Gini coefficientब \\
\hline Canada & 6.8 & 22940 & 1.5 & 0.33 \\
\hline China & $3.1^{*}$ & 845 & 1.8 & 0.45 \\
\hline Finland & 9.7 & 22156 & 1.7 & 0.26 \\
\hline France & 10.0 & 20428 & 1.8 & 0.33 \\
\hline Sweden & 4.7 & 25641 & 1.5 & 0.25 \\
\hline
\end{tabular}

variables. The regression models were first run for the whole study population using individual and country level covariates, and the analyses were then performed by country using the individual level adjustments. After the adjustment for the background characteristics and the intrinsic motivational factors, we tested whether there were overall differences in the associations between the intrinsic motivational factors and functional incapacity between individual countries, and whether the associations of the Chinese employees differed significantly from the associations found among the western employees.

\section{RESULTS}

Table 1 shows the characteristics of the study population. The population was male dominated in each country. The Chinese employees were younger than the employees from the other countries. In France there were more white collar employees than in the other countries. The Finnish and the Swedish employees reported less physical hazards at work than the employees in the other countries. A lower income, a lower unemployment rate, and higher wealth inequality were evident in China (table 2).

As table 3 shows, the levels of intrinsic motivational factors were similar in the countries studied, but some distinctive trends were also observed. The Swedish and the Chinese had the most innovative work environment ( $p$ value difference between countries $<0.001$ ). The Chinese also reported higher job autonomy than the employees from the other countries $(p<0.001)$. At the same time, they had the lowest job complexity whereas the French had the highest $(\mathrm{p}<.0 .001)$. The prevalence of functional incapacity followed a similar pattern across the countries, but the Canadian workers reported better functional capacity than the employees in the other countries.

Functional incapacity was partly related to age, sex, and SES, but not in all countries. In western countries, female and male employees had similar functional capacity, but in China women had more health problems than men (OR 1.6, 95\% CI 1.3 to 1.8). In Finland (OR 2.0, 95\% CI 1.8 to 2.1 ), Sweden (OR 1.6, 95\% CI 1.2 to 1.9), France (OR 6.0, 95\% CI 3.2to 11.3), and Canada (OR 2.6, 95\% CI 1.1 to 6.5) blue collar employees had a higher risk of functional incapacity than white collar employees in their own country (OR across countries 2.0, 95\% CI 1.8 to 2.2). A poor physical work environment was related to increased functional incapacity regardless of the grade of employment (OR 1.6, 95\% CI 1.4 to 1.7). The country level variables were rather weakly associated with functional incapacity.

After adjustment for age, sex, SES, and physical work environment, the risk of functional incapacity among the employees with low complexity or autonomy was about twofold compared with the employees with high job complexity or autonomy in the countries studied (table 4). However, functional incapacity was significantly more related to the lack of job complexity (test for difference $p=0.005$ ) and autonomy $(\mathrm{p}=0.04)$ in China. The effect of the third intrinsic motivational factor, innovativeness, differed significantly according to the country (test for difference between countries $\mathrm{p}=0.015)$. Especially in China and in Finland, employees were prone to functional incapacity if they had poor innovativeness at work, while similar, but weaker associations were found in other countries (test for difference between the two country blocks $\mathrm{p}=0.025$ ).

\section{DISCUSSION}

Western psychological theories on employees' health ${ }^{1-4}$ have suggested that creative, independent, and challenging work contribute to employee wellbeing. This view of intrinsic motivational factors as contributors to health has often been presented as a universal fact. In our cross national study, we examined the intrinsic motivational factors of work, functional incapacity, and their associations in five countries among the industrial employees working in similar occupations in the same globally operating multinational enterprise.

Of the intrinsic motivational factors, job autonomy was positively related to functional incapacity. This is in accordance with previous studies conducted in some western European countries ${ }^{6-11}$ and former eastern European socialist countries. ${ }^{14}$ Our finding emphasises the importance of decision latitude and independence at work for employee wellbeing regardless of the country. ${ }^{1}$ Furthermore, in line with previous individual research findings from some countries, ${ }^{57}$ the innovativeness of work associated positively with functional capacity, highlighting the focal role of an innovative atmosphere for good health in industrial work in various nations. Based on the theories of occupational

Table 3 The means (M) and the standard errors (SE) of intrinsic motivational factors of work and functional incapacity by country

\begin{tabular}{|c|c|c|c|c|c|c|c|c|c|c|c|c|c|}
\hline \multirow[b]{2}{*}{ Variable } & \multicolumn{2}{|c|}{$\begin{array}{l}\text { Canada } \\
(n=474)\end{array}$} & \multicolumn{2}{|c|}{$\begin{array}{l}\text { China } \\
(n=681)\end{array}$} & \multicolumn{2}{|c|}{$\begin{array}{l}\text { Finland } \\
(n=7567)\end{array}$} & \multicolumn{2}{|c|}{$\begin{array}{l}\text { France } \\
(n=526)\end{array}$} & \multicolumn{2}{|c|}{$\begin{array}{l}\text { Sweden } \\
(n=4511)\end{array}$} & \multicolumn{2}{|c|}{$\begin{array}{l}\text { Total } \\
(n=13759)\end{array}$} & \multirow{2}{*}{$\begin{array}{l}\text { Test for difference } \\
\text { between countries, } \\
\text { p value }\end{array}$} \\
\hline & $M$ & SE & $M$ & SE & $M$ & SE & $M$ & SE & $M$ & SE & M & SE & \\
\hline Innovation & 3.00 & 0.03 & 3.16 & 0.02 & 3.02 & 0.01 & 3.03 & 0.03 & 3.17 & 0.01 & 3.09 & 0.01 & 0.001 \\
\hline Complexity & 3.52 & 0.04 & 3.12 & 0.03 & 3.46 & 0.01 & 3.58 & 0.03 & 3.48 & 0.01 & 3.47 & 0.01 & 0.001 \\
\hline Autonomy & 3.19 & 0.04 & 3.75 & 0.03 & 3.46 & 0.01 & 3.48 & 0.04 & 3.47 & 0.01 & 3.45 & 0.01 & 0.001 \\
\hline $\begin{array}{l}\text { Functional } \\
\text { incapacity }\end{array}$ & 1.82 & 0.03 & 2.04 & 0.03 & 2.09 & 0.01 & 1.98 & 0.03 & 2.11 & 0.01 & 2.08 & 0.01 & 0.019 \\
\hline
\end{tabular}


Table 4 Odds ratios (OR) and their $95 \%$ confidence intervals (95\% Cl) for functional incapacity by work characteristics in five countries in the private industrial sector ${ }^{*}$

\begin{tabular}{|c|c|c|c|c|c|c|c|c|c|}
\hline & \multicolumn{3}{|c|}{ Canada $(n=474)$} & \multicolumn{3}{|c|}{ China $(n=681)$} & \multicolumn{3}{|c|}{ Finland $(n=7567)$} \\
\hline & $\mathrm{N}$ (\% cases) & OR & $95 \% \mathrm{Cl}$ & $\mathrm{N}$ (\% cases) & OR & $95 \% \mathrm{Cl}$ & $\mathbf{N}$ (\% cases) & OR & $95 \% \mathrm{Cl}$ \\
\hline \multicolumn{10}{|l|}{ Innovation } \\
\hline High & $116(2.6)$ & 1 & & $237(4.2)$ & 1 & & $1770(5.6)$ & 1 & \\
\hline Intermediate & 201 (11.9) & 3.20 & 0.96 to 10.66 & $266(11.6)$ & 2.03 & 1.00 to 4.11 & 3272 (13.5) & 2.07 & 1.68 to 2.56 \\
\hline Low & $157(10.8)$ & 2.99 & 0.88 to 10.19 & 178 (18.5) & 3.78 & 1.85 to 7.73 & $2525(21.8)$ & 3.04 & 2.47 to 3.74 \\
\hline \multicolumn{10}{|l|}{ Autonomy } \\
\hline High & 107 (3.7) & 1 & & $345(5.8)$ & 1 & & $2702(9.4)$ & 1 & \\
\hline Intermediate & $194(6.7)$ & 1.07 & 0.29 to 4.07 & 216 (12.5) & 2.15 & 1.15 to 4.01 & 2897 (14.5) & 1.48 & 1.28 to 1.71 \\
\hline Low & 173 (15.6) & 3.25 & 0.98 to 10.71 & $120(22.5)$ & 3.81 & 2.07 to 7.03 & $1968(21.4)$ & 1.99 & 1.71 to 2.30 \\
\hline \multicolumn{10}{|l|}{ Complexity } \\
\hline High & $149(6.7)$ & 1 & & $107(2.8)$ & 1 & & $2351(8.0)$ & 1 & \\
\hline Intermediate & $197(8.1)$ & 0.86 & 0.34 to 2.17 & $234(5.6)$ & 1.09 & 0.30 to 4.02 & 2725 (13.3) & 1.49 & 1.26 to 1.76 \\
\hline \multirow[t]{3}{*}{ Low } & $128(14.1)$ & 1.93 & 0.82 to 4.52 & 340 (17.1) & 3.85 & 1.21 to 12.27 & $2491(21.8)$ & 2.31 & 1.96 to 2.73 \\
\hline & \multicolumn{3}{|c|}{ France $(n=526)$} & \multicolumn{3}{|c|}{ Sweden $(n=4511)$} & \multicolumn{3}{|c|}{ All $(n=13759) \dagger$} \\
\hline & $\mathrm{N}$ (\% cases) & OR & $95 \% \mathrm{Cl}$ & $\mathrm{N}$ (\% cases) & OR & $95 \% \mathrm{Cl}$ & $\mathbf{N}$ (\% cases) & OR & $95 \% \mathrm{Cl}$ \\
\hline \multicolumn{10}{|l|}{ Innovation } \\
\hline High & $161(5.0)$ & 1 & & $1559(8.5)$ & 1 & & $3843(6.6)$ & 1 & \\
\hline Intermediate & 175 (11.4) & 1.49 & 0.61 to 3.62 & 1705 (14.4) & 1.58 & 1.27 to 1.96 & $5619(13.6)$ & 1.82 & 1.58 to 2.09 \\
\hline Low & $190(19.0)$ & 2.17 & 0.93 to 5.07 & $1247(21.0)$ & 2.23 & 1.80 to 2.76 & $4297(21.0)$ & 2.64 & 2.29 to 3.04 \\
\hline \multicolumn{10}{|l|}{ Autonomy } \\
\hline High & $186(6.4)$ & 1 & & $1654(9.5)$ & 1 & & $4994(8.9)$ & 1 & \\
\hline Intermediate & $199(13.1)$ & 1.92 & 0.88 to 4.15 & 1675 (13.9) & 1.40 & 1.13 to 1.71 & $5181(14.0)$ & 1.47 & 1.30 to 1.65 \\
\hline Low & 141 (18.4) & 2.07 & 0.95 to 4.51 & $1182(21.2)$ & 2.02 & 1.64 to 2.50 & $3584(21.0)$ & 2.02 & 1.80 to 2.27 \\
\hline \multicolumn{10}{|l|}{ Complexity } \\
\hline High & $192(4.7)$ & 1 & & $1370(9.6)$ & 1 & & $4169(8.2)$ & 1 & \\
\hline Intermediate & 195 (12.3) & 1.66 & 0.74 to 3.73 & 1808 (13.0) & 1.21 & 0.97 to 1.52 & $5159(12.6)$ & 1.36 & 1.19 to 1.55 \\
\hline Low & $139(22.3)$ & 2.86 & 1.29 to 6.33 & 1333 (20.4) & 1.90 & 1.51 to 2.39 & 4431 (20.9) & 2.19 & 1.93 to 2.50 \\
\hline
\end{tabular}

wellbeing, job autonomy is probably crucial for the health of employees, because greater autonomy associates with more possibilities to cope with stressful situations, ${ }^{1}$ whereas innovativeness may contribute to health, because it supports and allows a variety of ways to deal with the challenges at work, ${ }^{4}$ simultaneously alleviating the experienced stress at work. Finally, job complexity was also associated with a lower risk of poor functional incapacity in several countries. When faced with a job without challenges and task variety, employees may feel stressed, as the job offers only repetitive and dull tasks. ${ }^{32} 38$ The importance of reasonable intellectual discretion for health has been reported from some western countries previously, ${ }^{11}{ }^{13}$ but has not been found using cross national data from a global company.

We found that the functional incapacity of industrial employees in China was more strongly associated with intrinsic motivational factors of work than in western countries. It is possible that the Chinese, as employees of an economy in transition, may particularly value intrinsic motivational factors of work in their cultural context, because they are used to the systems of collective control and support, ${ }^{39}$ and individualistic facets of wellbeing have not been so clearly emphasised previously. In line with the sociocultural assumption, Kristenson and his colleagues ${ }^{40}$

\section{What the study adds}

- Similar associations between intrinsic motivational factors of work and functional incapacity were seen in different countries among the employees of a multinational company.

- The strength of the associations between intrinsic motivational factors and functional incapacity were stronger among the Chinese employees. reported that the prevalence of decision latitude, an important dimension of job autonomy, was much lower among randomly selected men of a post-socialist country, Lithuania, as compared with a corresponding sample of men in a western individualistic country, Sweden.

The findings suggest that innovating freely, functioning independently, and using multiple skills at work may improve the employees' wellbeing rather universally. This might also be related to the fact that there has been a strong tendency to globalise working practices, standardise production systems, and merge the values of the employees of global companies particularly during the past two decades. Consequently, there may be only minor differences between employees from different countries within multinational corporations. This finding is of high relevance, if we consider global industrial companies that increasingly employ people from several nationalities. It may be that psychological work characteristics play even a more significant part in employee wellbeing in non-western cultures, if these societies are transforming towards a westernised production environment and western economy, and the employees work in this kind of work environment.

\section{Policy implications}

- Regardless of the country, the management and the occupational health professionals of multinational corporations should be aware of the potential importance of intrinsic motivational factors for employee health.

- Intrinsic motivational factors may increasingly act as health resources, as development shifts towards greater material wellbeing and the need for self actualisation at work. 
Overall, the employees report rather similar levels of intrinsic motivational factors across the countries. For instance, the Canadians had nearly similar job autonomy as the employees in the Nordic countries, even though it has been suggested that in countries such as Canada rule oriented practices limit employee autonomy, whereas in countries such as Sweden and Finland skill oriented practices expand autonomy and complexity of work. ${ }^{23}$ The Chinese were the greatest exception, as they had a considerably higher level of job autonomy. This arouses a question regarding the culture specific understanding of the research items. Although the Chinese have been reported to select positive alternatives somewhat more frequently than people from the USA for instance, ${ }^{41}$ we do not believe that the employees in China report their autonomy incorrectly, because the Chinese did not systematically tend to respond positively to the other items. It is possible that the Chinese employees perceive advanced job autonomy in the multinational enterprise where they work compared with the habitual job autonomy of their traditional cultural setting, or these Chinese employees may be a rather selected group of employees in their cultural context. Finally, although the questionnaire was professionally translated into Chinese, some concepts may have a specific meaning in some culture/ language context that does not correspond exactly with the meaning of the concepts in some other culture/language context.

Because of cross sectional nature of the study, we could not draw any definitive conclusions regarding the time order of the associations between the intrinsic motivational factors and functional incapacity. When combined with previous longitudinal findings, ${ }^{569-14}$ the results suggest that the intrinsic motivational factors of work may decrease the risk of lowered wellbeing in the long run among employees with different cultural backgrounds. However, the causality ought to be verified by longitudinal cross national research. Furthermore, another limitation of the study was that the sample sizes varied by country, and that the response rate was rather low in France. This may limit somewhat the validity of our findings. To reveal universal and culture specific aspects of employee wellbeing, various methodological alternatives in cross national research should also be applied in the future. These include larger study populations involving different sectors, the use of other psychosocial measures, the use of medical health measures, health service evaluations, and qualitative culture sensitive studies.

The intrinsic motivational factors are not only associated with self assessed health indicators, but have other health consequences as well. ${ }^{6}{ }^{13} 32 \mathrm{Job}$ autonomy itself is also stated to be an important component of national economic competitiveness. ${ }^{23}$ Therefore, high autonomy may be regarded as a sign of good management strategies that improve the productivity and competitiveness of the companies functioning in these countries. Also innovativeness has proved to increase productivity. ${ }^{4}$ It is therefore plausible that the development of the work environment by improving the intrinsic motivational factors may reduce both financial costs and registered health problems in various countries. The intrinsic motivational factors may increasingly act as resources of employee wellbeing, as development shifts towards greater material wellbeing, the need for self actualisation at work, and overall individualisation, especially among the employees of the multinational corporations throughout the world.

\footnotetext{
Authors' affiliations

A Väänänen, K Pahkin, P Huuhtanen, R Kalimo, Finnish Institute of Occupational Health (FIOH), Department of Psychology, Helsinki, Finland
}

M Kivimäki, University of Helsinki, Department of Psychology, Division of Applied Psychology, Helsinki, Finland

J Vahtera, Finnish Institute of Occupational Health, Turku, Finland T Theorell, National Institute for Psychosocial Factors and Health, Karolinska Institute, Stockholm, Sweden

Funding: the study was supported by the University of Tampere, the Academy of Finland (projects no 77560, no 105195), Yriö Jahnsson Foundation (project no 5082), the Finnish Work Environment Fund (projects no 101190 and no 103432), the Finnish Institute of Occupational Health and StoraEnso Oyj.

Conflicts of interests: none.

\section{APPENDIX}

\section{THE SCALES OF INTRINSIC MOTIVATIONAL FACTORS AND FUNCTIONAL INCAPACITY Innovativeness}

- How much interaction exists in your work unit?

- Does the atmosphere of your work unit (department, work group or equivalent) encourage one to be innovative and to develop new ways of action?

- I experiment with new things in my work

- Do you get help and support from others in implementing your ideas?

- Do you collaborate with others in order to develop new ideas?

- How are proposals for improvement responded to in your work unit (department, work group or equivalent)?

- Are work results appraised justly in your work unit?

\section{Job autonomy}

- Can you set your own working pace?

- Can you leave your working area without somebody taking over?

- Can you plan your work yourself?

- How is your work carried out?

- How much influence do you have on the objectives of your work (i.e. on what you are expected to achieve)?

\section{Job complexity}

- Is your work monotonous or variable?

- Can you use your knowledge and skills in your work?

- Does your work require thinking and weighing decisions?

- At work, do you repeat the same partial task or tasks?

- Do you have to keep on learning new things in your work?

\section{Functional incapacity}

- How is your health compared to persons of the same age?

- How would you evaluate your present working capacity regarding the physical requirements of your work?

- How would you evaluate your present working capacity regarding the psychological requirements of your work?

\section{REFERENCES}

1 Theorell T. To be able to exert control over one's situation: a necessary condition for coping with stressors. In: Campbell Quick JC, Tetrick LE, eds. Handbook of occupational health psychology. Washington: APA, 2003:201-19.

2 Belkic K, Schnall P, Savic C, et al. Stressors at the workplace: theoretical models - multiple exposures: toward a model of total occupational burden, Occup Med 2000;15:94-8.

3 Levi L. Stressors at the workplace: theoretical models - a historical overview. Occup Med 2000; 15:69-73. 
4 West MA, Farr JL, eds. Innovation and creativity at work: psychological and organizational strategies. Chichester: Wiley, 1990.

5 Kivimäki $M$, Sutinen R, Elovainio $M$, et al. Sickness absence in hospital physicians: 2 years follow up study on determinants. Occup Environ Med 2001;58:361-6.

6 Vahtera J, Kivimäki M, Pentti J, et al. Effect of change in the psychosocial work environment on sickness absence: a seven year follow up of initially healthy employees. J Epidemiol Community Health 2000;54:484-93.

7 Aronsson G, Bejerot E, Härenstam A. Healthy work: ideal and reality among public and private employed academics in Sweden. Public Personnel Management 1999;28:197-215.

8 Theorell T, Tsutsumi A, Hallquist J, et al. Decision latitude, job strain, and myocardial infarction: a study of working men in Stockholm. The SHEEP Study Group. Stockholm heart epidemiology program. Am J Public Health 1998;88:382-8.

9 Bultmann U, Kant IJ, Van den Brandt PA, et al. Psychosocial work characteristics as risk factors for the onset of fatigue and psychological distress: prospective results from the Maastricht cohort study. Psychol Med 2002;32:333-45.

10 Houtman ILD, Bongers PM, Smulders PGW, et al. Psychosocial stressors at work and musculoskeletal problems. Scand J Work Environ Health 1994;20:139-45.

11 Van Mierlo H, Rutte CG, Seinen B, et al. Autonomous teamwork and psychological well-being. European Journal of Work and Organizational Psychology 2001;10:291-301.

12 North FM Syme SL, Feeney A, et al. Psychosocial work environment and sickness absence among British civil servants: the Whitehall II study. Am J Public Health 1996;86:332-40

13 Stansfeld S, Fuhrer R, Head J, et al. Work and psychiatric disorders in the Whitehall II study. J Psychosom Res 1997:43:73-81.

14 Malinauskiene V, Theorell T, Grazuleviciene R, et al. Low job control and myocardical infarction risk in the occupational categories of Kaunas men, Lithuania. J Epidemiol Community Health 2004;58:131-5.

15 Rose N. Governing the soul: the shaping of the private self. London: Routledge, 1990.

16 Danziger K. Constructing the subject: historical origins of psychological research. Cambridge: Cambridge University Press, 1990.

17 Maslow AH. Motivation and personality. New York: Harper and Row, 1954

18 Hetzberg F, Mausner B, Snyderman BB. The motivation to work. New York: Wiley, 1959

19 Diener E, Suh EM, eds. Culture and subjective well-being. Cambridge, MA: MIT Press, 2000.

20 Huang $\mathbf{X}$. Just a matter of taste? One nation's job satisfiers are another nation's job dissatisfiers. Veenendaal: Universal Press, 2002

21 MOW (Meaning of Work) International Research Team. The meaning of working. London: Academic Press, 1987.

22 Lundberg CD, Peterson MF. The meaning of working in U.S. and Japaniese local governments at three hierarchical levels. Human Relations 1994;47:1459-87.
23 Dobbin F, Boychuk T. National employment systems and job autonomy: Why job autonomy is high in the Nordic countries and low in the United States, Canada, and Austria. Organizational Studies 1999;20:257-91.

24 Kristenson M, Kucinskiene Z, Bergdahl B, et al. Increased psychosocial strain in Lithuanian versus Swedish men: the LiVicordia study. Psychosom Med 1998;60:277-82

25 Truss C, Goffee R, Jones G. Segregated occupations and gender stereotyping: a study of secreterial work in Europe. Human Relations 1995;48:1331-54.

26 Diener E, Diener M, Diener C. Factors predicting the subjective well-being of nations. J Pers Soc Psychol 1995:69:851-64.

27 Sousa-Poza A, Sousa-Poza AA. Well-being at work: a cross-national analysis of the levels and determinants of job satisfaction. Journal of Socio-Economics 2000;29:517-38.

28 Defrank RS, Ivancevich JM, Schweiger DH. Job stress and psychological wellbeing: similarities and differences among American, Japanese and Indian managers. Behav Med 1995; 14:160-70.

29 Spector PE, Cooper CL, Sanchez JL, et al. Do national levels of individualism and internal locus of control relate to well-being: an ecological level international study. J Organiz Behav 2001 ;22:815-32.

30 Väänänen A, Pahkin K, Kalimo R, et al. Maintenance of subjective health during a merger: The role of experienced change and pre-merger social support at work in white- and blue-collar workers. Soc Sci Med 2004;58:1903-15.

31 Toppinen-Tanner S, Kalimo R, Mutanen P. The process of burnout in whitecollar and blue-collar jobs: eight-year prospective study of exhaustion. Journal of Organizational Behavior 2002;23:1-16.

32 Väänänen A, Toppinen-Tanner S, Kalimo R, et al. Job characteristics, physical and psychological symptoms, and social support as antecedents of sickness absence among men and women in the private industrial sector. Soc Sci Med 2003; 57:807-24

33 Tuomi K, Ilmarinen J, Jahkola A, et al. Work ability index. Helsinki: The Finnish Institute of Occupational Health, 1998.

34 Tuomi K, Huuhtanen P, Nykyri E, et al. Promotion of work ability, the quality of work and retirement. Occup Med 2001:51:318-24.

35 OECD. Society at a glance. OECD social indicators. Paris: Organization for Economic Co-operation and Development, 2001.

36 United Nations. Human development report 2004. New York: United Nations Development Programme, 2004.

37 Kalimo E. OECD social indicators for 2001: a critical appraisal. Social Indicators Research 2005;70:185-229.

38 Wills TA. Social comparison processes in coping and health. In: Snyder CR Forsyth DR, eds. Handbook of social and clinical psychology: the health perspective. New York: Pergamon, 1991:376-94.

39 Shaw VN. Social control in China: a study of Chinese work units. Westfort: Praeger Publishers, 1996.

40 Kristenson M, Kucinskiene Z, Bergdahl B, et al. Increased psychological strain in Lithuanian versus Swedish men: the LiVicordia study. Psychosom Med 1998:60:277-82.

41 Lee JW, Jones PS, Mineyama Y, et al. Cultural differences in responses to a Likert scale. Res Nurs Health 2002;25:295-306. 